\title{
Health Effects of Indoor Emissions Combining Outdoor and Indoor Pollution Simulations
}

\author{
Roberto San José, Juan L. Pérez, Libia Pérez, and Rosa M. González
}

\begin{abstract}
The aim of the paper is to show that it is very important to take into account indoor pollution when studying the health effects of the quality of the air we are breathing. The simulations must consider the indoor emissions because they are the ones that make the concentrations of the air that we breathe are different from the outdoor concentrations. We have performed a simulation exercise of air quality both outdoor and indoor in 2 buildings (office and home) located in the center of Madrid (Spain), with different scenarios of indoor emissions to isolate their impacts. The simulations are run over full year 2016 with hourly outputs. The simulations must also model atmospheric dynamics to produce meteorological data that will be key to indoor simulations. Exposure to pollutant concentrations has been calculated based on a predefined pattern that indicates where the person is at each time. In indoor pollution simulations it is very important to model all the physical processes that affect concentrations, such as: emission, infiltration, deposition, mechanical and manual ventilation (closely related to the thermal comfort range of the building) and air exchange between rooms through the doors. The highest impact on health is produced by the emissions that are released when people are cooking.
\end{abstract}

Index Terms-Exposure, health impact, indoor pollution, outdoor simulation.

\section{INTRODUCTION}

In general, the ventilation increases indoor pollution coming from outdoor sources, especially in high polluted environments. There are several factors that affect how external pollution infiltrates buildings: the location of the building, the permeability of its surface, ventilation systems, weather conditions, and the behavior of building occupants (opening windows and switching HVAC systems off and on). But the concentrations inside the building not only depend on what comes in from outside but also on the sources of internal emissions [1]. Elimination of indoor and outdoor air contaminants from indoor and outdoor air sources can be produced by exfiltration, deposition on the surface and by filtration using mechanical ventilation equipment. The objective is to reduce the energy demand of the ventilation systems but getting a healthy indoor environment for the people. But, when the simulation of energy and indoor air quality are separate, the combined effects are not simulated

Manuscript received April 12, 2019; revised August 29, 2019.

Roberto San José, Juan L. Pérez, and Libia Pérez are with Environmental Software and Modelling Group, Computer Science School, Technical University of Madrid (UPM), Madrid, Spain (e-mail: roberto@fi.upm.es, jlperez@fi.upm.es, lperez@fi.upm.es).

R. M. Gonzalez is with Department of Physics and Meteorology, Faculty of Physics, Complutense University of Madrid (UCM), Ciudad Universitaria, 28040 Madrid, Spain (e-mail: rgbarras@fis.ucm.es). and it is impossible to get the objective.

All these physical processes (view Fig. 1) must be simulated at the same time, together with the thermal environment inside the rooms of the buildings in order to have a realistic estimate of the concentrations of pollutants in the buildings, for which it is necessary to implement an integrated model such as the one used in this work. Information on the indoor/outdoor $(\mathrm{I} / \mathrm{O})$ relationship of concentrations of air pollutants is a crucial component in human exposure and indoor environmental health impact assessments. There are many challenges in conducting the $\mathrm{I} / \mathrm{O}$ study due to the presence of many influential factors, such as outdoor climate and pollutant concentrations, indoor ventilation and infiltration rates, source strength, human activities, and so on.

Air pollution epidemiological studies have identified the short term associations of daily mortality and morbidity of populations with respective daily ambient air (outdoor air) pollution monitoring data [2]. Traditionally, these works focus on concentrations of outdoor pollution [3] and the health of the population and do not take into account indoor air pollution [4]. Previous health impact assessment studies have generally used outdoor concentrations, but most people spend a very high portion of their total indoor time [5].

Concentrations of air pollutants are often much higher inside buildings than outside [6]. In addition, fixed-site and outdoor monitors do not adequately estimate human exposure to most air pollutants. The high degree of variability of pollutant concentrations within buildings, in neighborhoods, and in cities will require substantial work to determine the distribution of exposures among the population, this work being a start toward that goal. Accurate estimates of human exposure to inhaled air pollutants are needed for a realistic assessment of the risks posed by these pollutants and for the design and implementation of strategies to control and limit these risks. Simulation models are useful tools for quantifying the relationship between exposure to air pollutants and important explanatory variables (e.g. time and activity patterns), as well as for estimating exposures in situations where measurements are not available.

The novelty of this study is that it uses outdoor concentrations and simulated meteorology to know the indoor concentrations of the building, since until now studies of indoor contamination levels have used data measured by nearby monitoring stations. Our simulation tool allows to make future simulations of the outdoor and indoor pollution how is described in the next sections, so it is a simulation and forecasting tool. Because of air exchange, indoor pollutant levels are generally higher when outdoor levels increase. However, higher levels can be found indoors when combustion sources are present [7]. 


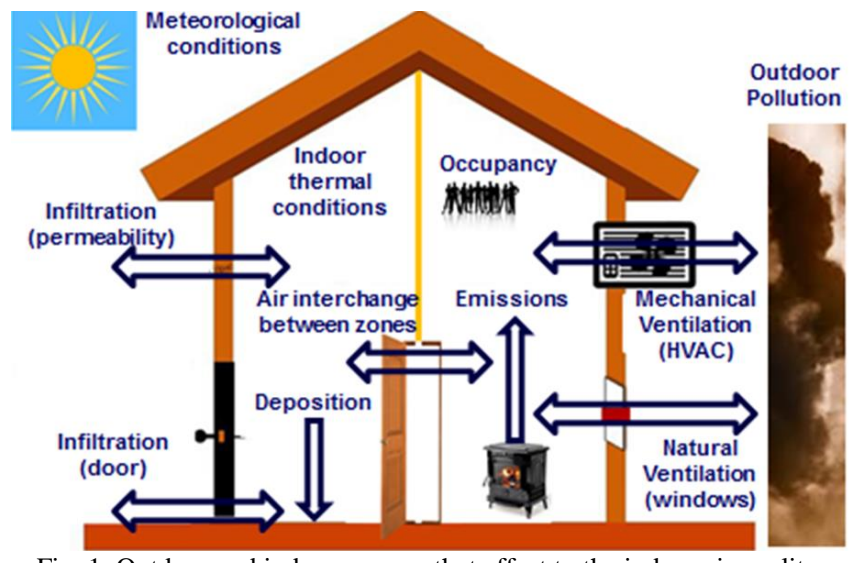

Fig. 1. Outdoor and indoor process that affect to the indoor air quality.

\section{Methodology}

Outdoor air quality and meteorological simulation has been run with the EMIMO-WRF/Chem modelling system. WRF-Chem [8] is the Weather Research and Forecasting (WRF) model coupled with Chemistry. WRF is 3-D non-hydrostatic prognostic model that simulates mesoscale atmospheric circulations. Chem model simulates the emission, transport, mixing, and chemical transformation of trace gases and aerosols simultaneously with the meteorology. Emissions are provided by the EMIMO model (UPM) [9].

Indoor air quality and energy simulations have been run with the EnergyPlus [10] model for an office and house buildings. A building is a complex thermodynamic object that accommodates constantly changing energy flows between the different thermal zones within the building and the outside. The two main components of the building energy simulation model are: A) the building fabric and the content (walls, floors, ceilings, occupants and equipment) and B) the plant components (HVAC equipment and other environmental control systems). EnergyPlus is the U.S. Department of Energy's 3rd generation dynamic building energy simulation engine for modeling building, heating, cooling, lighting ventilating and indoor pollution. The Generic Contaminant Model in EnergyPlus allows for the integrated modelling of multizone contaminant and dynamic thermal behaviour within a single simulation package [11].

A $130 \mathrm{~m} 2$ north-facing office building in the centre of Madrid has been simulated. The office has three rooms and the north room is where our reference person is when working The heating, ventilation and air condition system (HVAC) is a three zone central system using single air loop. Electrical cooling coils provide space cooling. Cooling coil on in warm period (01/04 - 30/09). Gas heating coils provide heating. Heating coil on all year. Mechanical ventilation on for cooling and heating. Heating set point is $22^{\circ} \mathrm{C}$ and cooling set point is $24^{\circ} \mathrm{C}$. The simulated house building is on the office building with same size and orientation and four rooms (bedroom, bathroom, kitchen and living-room). The reference person lives with other person with the same time schedule. The HVAC is similar to the office ones. Electrical cooling coils provide space cooling. Cooling coil on in warm period (01/04 - 30/09). Gas heating coils provide heating. Heating coil on non-warm periods $(01 / 01-30 / 03$ and $01 / 10-31 / 12)$. Natural ventilation, 1 hour on the morning (window bedroom).
Heating and cooling coils on when people are in the house (domotic house) and comfort temperature range $22^{\circ}$ (heating) and $24^{\circ}$ (cooling).

Activity patterns have been defined to calculate the exposure of an individual person. We have calculated a personal or individual exposure (Table I), i.e. the concentrations of pollutants experienced by an individual during normal daily activities (one profile for weekdays and one for weekends). Personal exposure depends on the concentrations of contaminants present in the rooms of the house, the office room and outdoor contamination (the places the person spends time in), as well as the time spent in each place. Exposure assessment combines the concentrations of pollutants modeled at fixed locations (home, office, and outdoor) and the time the person spends at specific locations.

\begin{tabular}{cc} 
TABLE I: INDIVIDUAL EXPOSURE PATTERN \\
\hline \hline Week day & Location \\
\hline $00-07 \mathrm{~h}$ & Bedroom \\
$07-08 \mathrm{~h}$ & Bathroom/Kitchen \\
$08-14 \mathrm{~h}$ & Office \\
$14-15 \mathrm{~h}$ & Kitchen \\
$15-16 \mathrm{~h}$ & Livingroom \\
$16-18 \mathrm{~h}$ & Office \\
$18-21 \mathrm{~h}$ & Outdoor \\
$21-22 \mathrm{~h}$ & Kitchen \\
$22-00 \mathrm{~h}$ & Livingroom \\
\hline Weekend & \\
\hline $01-10 \mathrm{~h}$ & Bedroom \\
$10-11 \mathrm{~h}$ & Bathroom/Kitchen \\
$11-14 \mathrm{~h}$ & Outdoor \\
$14-15 \mathrm{~h}$ & Kitchen \\
$15-17 \mathrm{~h}$ & Livingroom \\
$17-22 \mathrm{~h}$ & Outdoor \\
$22-23 \mathrm{~h}$ & Kitchen \\
$23-01 \mathrm{~h}$ & Livingroom \\
\hline \hline
\end{tabular}

TABLE II: RELATIVE RISKS (RRS) FOR THE HEALTH IMPACT ASSESSMENT

\begin{tabular}{|c|c|c|}
\hline \multicolumn{3}{|c|}{ MORTALITY } \\
\hline $\begin{array}{l}\text { Pollutant } \\
\text { metric }\end{array}$ & $\begin{array}{c}\text { Health } \\
\text { Outcome }\end{array}$ & $\begin{array}{c}\text { RR } \\
(95 \% \mathrm{CI}) \\
\text { per } 10 \mathrm{ug} / \mathrm{m}^{3}\end{array}$ \\
\hline $\begin{array}{l}\mathrm{NO} 2 \text {, daily } \\
\text { maximum } \\
\text { 1-hour mean }\end{array}$ & $\begin{array}{c}\text { Mortality, all } \\
\text { (natural) causes, all } \\
\text { ages }\end{array}$ & $\begin{array}{c}1.0027 \\
(1.0016-1.0038)\end{array}$ \\
\hline PM25, daily mean & $\begin{array}{c}\text { Mortality, all } \\
\text { (natural) causes, all } \\
\text { ages }\end{array}$ & $\begin{array}{c}1.0123 \\
(1.0045-1.0201)\end{array}$ \\
\hline \multicolumn{3}{|c|}{ MORBIDITY } \\
\hline $\begin{array}{l}\text { NO2, daily } \\
\text { maximum } \\
\text { 1-hour mean }\end{array}$ & $\begin{array}{c}\text { Hospital } \\
\text { admissions, } \\
\text { respiratory } \\
\text { diseases, all ages }\end{array}$ & $\begin{array}{c}1.0015 \\
(0.9992-1.0038)\end{array}$ \\
\hline PM25, daily mean & $\begin{array}{c}\text { Hospital } \\
\text { admissions, } \\
\text { cardiovascular } \\
\text { diseases, all ages }\end{array}$ & $\begin{array}{c}1.0091 \\
(1.0017-1.0166)\end{array}$ \\
\hline PM25, daily mean & $\begin{array}{c}\text { Hospital } \\
\text { admissions, } \\
\text { respiratory } \\
\text { diseases, all ages }\end{array}$ & $\begin{array}{c}1.0190 \\
(0.9982-1.0402)\end{array}$ \\
\hline
\end{tabular}

Short term health impact assessment of different indoor emission scenarios has been done following BENMAP (EPA) methodology [12]. The percentage change in mortality/morbidity due to change in ambient exposure variable is derived from relative risks (RR) as estimated in 
epidemiological studies, assuming log-linear relationships between exposure and RR [13]. The RR values used are recommended by the HRAPIE project (Recommendations for concentration-response functions for cost-benefit analysis of particulates, ozone and nitrogen dioxide). For the mortality and morbidity analysis the following exposure-response (E-R) relationships from studies were used (Table II).

The objective is to develop a health impact assessment of different emissions scenarios. The impacts are calculated from a base scenario without indoor emissions called S0.
Table III describes the emission scenarios. For all scenario the $\mathrm{NO}_{2}$ deposition rate is $2.0 \mathrm{E}-4 \mathrm{~m}^{3} / \mathrm{s}$ [13] and for PM2.5 5.0E-5 $\mathrm{m}^{3} / \mathrm{s}$ [14]. Using the health impact assessment module we calculate the estimated change in human mortality and morbidity between different emissions.

Outdoor air quality and indoor simulations has been run over Madrid during 2016 year. Indoor air quality simulations have been run for a house and office buildings located in the Madrid city center.

TABLE III: DESCRIPTION OF THE EMISSION SCENARIOS

\begin{tabular}{|c|c|c|c|c|c|}
\hline Scenario & $\begin{array}{c}\text { Emission } \\
\text { source }\end{array}$ & $\begin{array}{l}\text { Location of the } \\
\text { source }\end{array}$ & $\begin{array}{l}\text { Time } \\
\text { Profile }\end{array}$ & Emissions & Reference \\
\hline S0 & $\begin{array}{c}\text { No } \\
\text { emissions }\end{array}$ & - & - & - & - \\
\hline $\mathrm{S} 1$ & $\begin{array}{l}\text { Photocopy } \\
\text { machine }\end{array}$ & $\begin{array}{l}\text { North room } \\
\text { of the office }\end{array}$ & Weekdays 07-18 & $\begin{array}{l}\text { PM2.5: 6.7E-9 } \\
\text { m3/s }\end{array}$ & {$[15]$} \\
\hline $\mathrm{S} 2$ & Gas stove & $\begin{array}{l}\text { Kitchen of } \\
\text { the house }\end{array}$ & $\begin{array}{c}\text { Weekdays: } 7: 30 \text { to } 08: 00, \\
14: 00-15: 00 \text { and } 21: 00 \text { to } 22: 00 \\
\text { Weekend days: } 10: 30 \text { to } 11: 00 \text {, } \\
14: 00-15: 00 \text { and } 22: 00 \text { to } 23: 00\end{array}$ & $\begin{array}{l}\mathrm{NO}_{2}: 56 \mathrm{ug} / \mathrm{s} \\
\mathrm{PM} 2.5: 1.56 \\
\mathrm{mg} / \mathrm{min}\end{array}$ & [16] \\
\hline S3 & $\begin{array}{l}\text { Oven for } \\
\text { heating }\end{array}$ & $\begin{array}{l}\text { Living room } \\
\text { of the house }\end{array}$ & $\begin{array}{c}\text { Cold periods ; } \\
\text { Weekdays:15:00 to } 16: 00 \text { and } 22: 00 \\
\text { to } 00: 00 \\
\text { Weekend days: } 15: 00 \text { to } 17: 00 \text { and } \\
\text { 23:00 to } 01: 00\end{array}$ & $\begin{array}{l}\mathrm{NO}_{2}: 3.0 \mathrm{E}-8 \\
\quad \mathrm{~m} 3 / \mathrm{s}\end{array}$ & [17] \\
\hline S4 & $\begin{array}{l}\text { One person, } \\
\text { two } \\
\text { cigarettes/hour }\end{array}$ & $\begin{array}{l}\text { Living room } \\
\text { of the house }\end{array}$ & $\begin{array}{l}\text { Weekdays: } 15: 00 \text { to } 16: 00 \text { and } 22: 00 \\
\text { to } 00: 00 \\
\text { Weekend days } 15: 00 \text { to } 17: 00 \text { and } \\
23: 00 \text { to } 01: 00\end{array}$ & $\begin{array}{l}\text { PM2.5: } 0.33 \\
\mathrm{mg} / \mathrm{min}\end{array}$ & [18] \\
\hline S5 & $\begin{array}{l}\text { Two people, } \\
\text { two } \\
\text { cigarettes/hour }\end{array}$ & $\begin{array}{l}\text { Living room } \\
\text { of the house }\end{array}$ & $\begin{array}{l}\text { Weekdays: } 15: 00 \text { to } 16: 00 \text { and } 22: 00 \\
\text { to } 00: 00 \text { Weekend days } 15: 00 \text { to } 17: 00 \\
\text { and } 23: 00 \text { to } 01: 00\end{array}$ & $\begin{array}{l}\text { PM2.5: } 0.66 \\
\mathrm{mg} / \mathrm{min}\end{array}$ & [19] \\
\hline
\end{tabular}

\section{RESULTS}

Outdoor simulation evaluation is performed based on comparison of simulated and observed air pollution concentrations at 43 monitoring stations of the Madrid air quality monitoring networks for the year 2016. Fig. 2 shows the Taylor diagram for the NO2 pollutant, it allows to compare modelled values versus measurement values. We can observe, the values of $\mathrm{R}^{2}$ are between 0.7 and 0.8 In all station locations, the mean square error of the central root (CRMSE) is less than 1 (except 24 monitoring station) and values are between 0.5 and 1.0. The ratios of the standard deviation between modeled and measured values are around 1.

The Fig. 3 shows the monthly mean of daily mortality change $(\%)$ due to $\mathrm{NO}_{2}$ indoor emissions for the emission scenarios S2 (cooking) and S3 (oven for heating). The changes in mortality are steady enough every month. In scenario S3 no impacts are observed during the warm months because the oven is not used for heating. In the warm months, a moderate increase in mortality is observed as a consequence of the use of the air conditioning system. The average annual mortality increase due to $\mathrm{NO} 2$ emissions from cooking is $0.59 \%$. While the average annual increase in mortality from the use of the heating oven is $0.21 \%$. The Fig. 4 shows the monthly mean of the daily hospital admissions by respiratory causes due to PM2.5 indoor emissions for the scenario S1 (photocopy), S2 (cooking) and S3 (smoke two people). The photocopy machine produces an increase of $0.27 \%$ (annual mean) in hospital admissions due to respiratory causes. The particles emitted when smoking 2 people, increases the daily hospital admissions in $0.21 \%$ of yearly average.

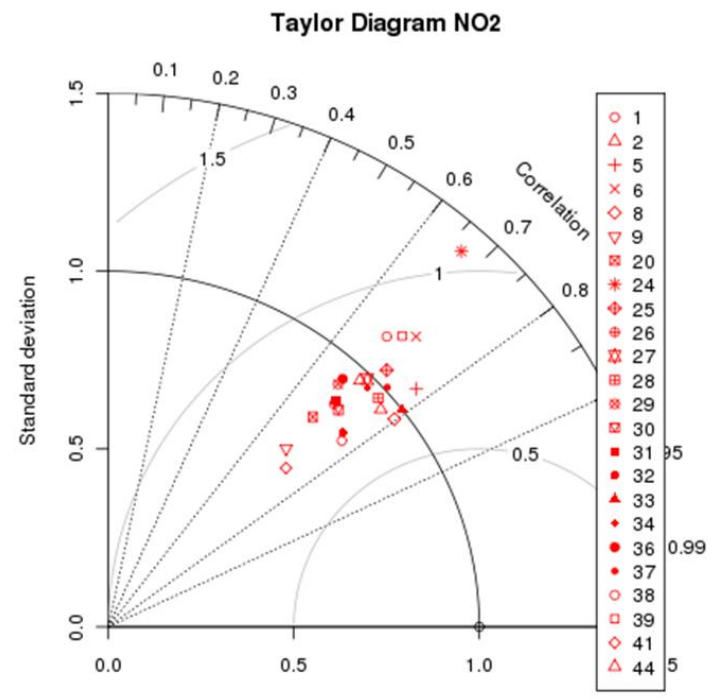

Fig. 2. Outdoor simulation evaluation. Taylor diagram for $\mathrm{NO}_{2}$

The maximum impact on health is due to emissions for cooking ( $0.36 \%$ annual mean). The highest impact on health is produced by the emissions that are released when cooking. A $0.59 \%$ annual mean increase in natural cause daily mortality due to exposure to $\mathrm{NO}_{2}$ concentrations has been observed, but we can analyze the impacts of every day. The 
Fig. 5 shows the daily variability of the mortality change due to gas stove emissions. The impacts are higher in the warm period due to the operation of the air conditioning. In the months of March and October are observed the days of lower impacts, not having to operate the HVAC to maintain the temperature range $\left(22^{\circ} \mathrm{C}-24^{\circ} \mathrm{C}\right)$.
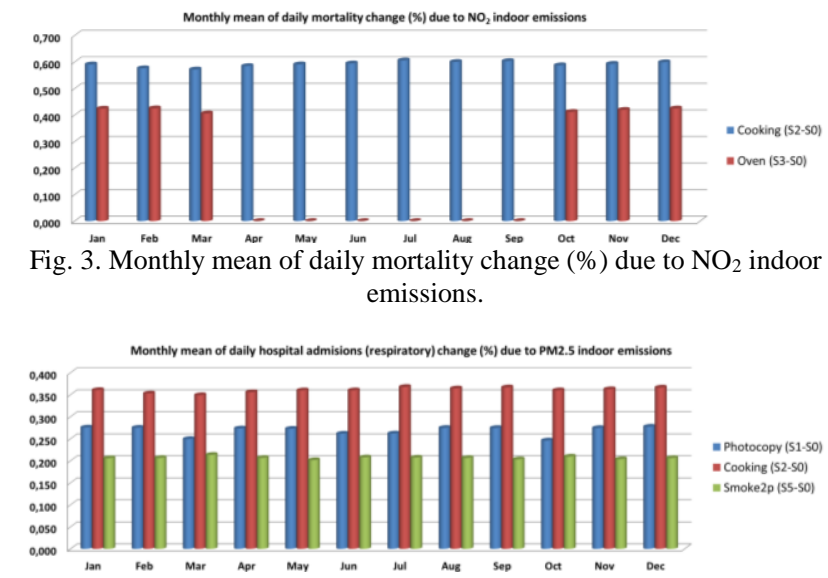

Fig. 4. Monthly mean of daily hospital admissions change (\%) due to PM2.5 indoor emissions.

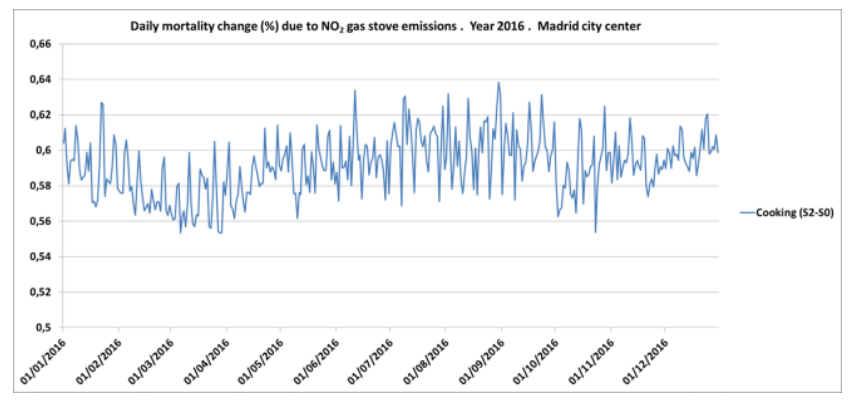

Fig. 5. Daily mortality change (\%) due to $\mathrm{NO}_{2}$ gas stove emissions. Year 2016. Madrid city center.

\section{CONCLUSIONS}

A short-term health impact assessment of different indoor emission scenarios has been done. The concentrations at which the reference person has been exposed have been calculated on the basis of predefined activity patterns. To calculate the exposure it was necessary to run an outdoor simulation and two indoor simulations: office and home. The outdoor air quality simulation was implemented with the EMIMO-WRF/Chem (emission-meteorological-chemical model).

The indoor simulations were run with the EnergyPlus model, which also takes into account the energy consumed and the operation of the HVAC system (thermal and ventilation process). The EMIMO-WRF/Chem has been used to provide outdoor pollution and meteorological inputs to the indoor air quality/energy model.

The simulation period is 2016. The WRF/Chem simulation includes 3 nesting domains up to $1 \mathrm{~km}$ spatial resolution and 1 hour of temporal resolution. Model results concentrations have been compared to measured data provided by 47 monitoring sites for year 2016. EMIMO-WRF/Chem fulfils all criteria for correlation, bias, standard deviation and RMSEu < 1 (100\% of satiations) for PM25 and NO2, so it can be used for applications. The evaluation of the performance has been very satisfactory.
The health impacts of emissions from a photocopy machine, the estimated emissions from cooking, those produced by an oven for heating and finally the emissions from smoking 1 and 2 people 2 cigarettes per hour have been studied. The methodology follows the ON-OFF or zero-out technique.

The results show a high correlation between indoor and outdoor concentrations when indoor emissions are not considered. However, in the case of indoor emissions, the indoor concentrations are totally different from the outdoor ones. This demonstrates the importance of taking into account the concentrations that people are breathing inside buildings to assess health impacts, and most of the time people are indoors.

The highest impact on health is produced by the emissions that are released when cooking. A $0.59 \%$ annual mean increase in natural cause daily mortality due to exposure to NO2 concentrations has been observed. The photocopy machine produces an increase of $0.27 \%$ in hospital admissions due to respiratory causes. The particles emitted when smoking 2 people, increases the daily hospital admissions in $0.21 \%$ of yearly average.

The health impacts of emitting sources are highest in the warm months due to the operation of the air conditioning system. While the lowest impacts occur when the air conditioning and heating are not working (transition days between warm and cold periods, March and October).

\section{CONFLICT OF INTEREST}

The authors declare no conflict of interest.

\section{AUTHOR CONTRIBUTIONS}

Roberto San José conducted the research; Juan Luis Pérez ran the simulations; Libia Pérez supervised the computer platform; Rosa M. Gonzalez Barras analyzed the meteorological and air pollution data; all authors had approved the final version.

\section{ACKNOWLEDGMENT}

The UPM authors thankfully acknowledge the computer resources, technical expertise and assistance provided by the Centro de Supercomputación y Visualización de Madrid (CESVIMA).

\section{REFERENCES}

[1] C. Shrubsole et al., "Indoor PM2.5 exposure in London's domestic stock: Modelling current and future exposures following energy efficient refurbishment," Atmos Environ., 2012, vol. 62, pp. 336-343.

[2] A. Analitis et al., "Short-term effects of ambient particles on cardiovascular and respiratory mortality," Epidemiology, 2006, vol. 17, no. 2, pp. 230-233.

[3] M. Bell, F. Dominici, and J. Samet, "A meta-analysis of time-series studies of ozone and mortality with comparison to the national morbidity, mortality, and air pollution study," Epidemiology, 2005, vol. 16, no. 4, pp. 436-445.

[4] R. Atkinson et al., "Long-term exposure to outdoor air pollution and incidence of cardiovascular diseases," Epidemiology, 2013, vol. 24, no. 1, pp. 44-53.

[5] C. Schweizer et al., "Indoor time-microenvironment-activity patterns in seven regions of Europe," J Expo Sci Environ Epidemiol., 2006, vol. 17, no. 2, pp. 170-181.

[6] J. Spengler and K. Sexton, "Indoor air pollution: A public health perspective," Science, 1983, vol. 221, no. 4605, pp. 9-17. 
[7] J. Levy, "Impact of residential nitrogen dioxide exposure on personal exposure: An international study," J Air Waste Manage Assoc., 1998, vol. 48 , no. 6 , pp. $553-560$

[8] G. Grell et al., "Fully coupled "online" chemistry within the WRF model," Atmos Environ., 2005, vol. 39, no. 37, pp. 6957-6975.

[9] R. González et al., "European operational air quality forecasting system by using MM5-CMAQ-EMIMO tool," Simulation Modelling Practice and Theory, 2008, vol. 16, no. 10, pp. 1534-1540.

[10] F. Winkelmann et al., "EnergyPlus: Creating a new-generation building energy simulation program," Energy Build, 2001, vol. 33, no. 4, pp. 319-331.

[11] M. Davies, "Simulation of pollution transport in buildings: the importance of taking into account dynamic thermal effects," Building Services Engineering Research and Technology, 2014, vol. 35, no. 6 , pp. 682-690.

[12] Y. Zhu et al., "The environmental benefits mapping and analysis program - Community edition (BenMAP-CE): A tool to estimate the health and economic benefits of reducing air pollution,' Environmental Modelling \& Software, 2018, vol. 104, pp. 118-129.

[13] S. Emmerich et al., "Modeled infiltration rate distributions for U.S. housing," Indoor Air, 2010, vol. 20, no. 6, pp. 473-485.

[14] C. Long et al., "Using time- and size-resolved particulate data to quantify indoor penetration and deposition behaviour," Environ $S c i$ Technol., 2001, vol. 35, no. 22, pp. 4584-4584.

[15] H. Destaillats et al., "Indoor pollutants emitted by office equipment: A review of reported data and information needs," Atmos Environ., 2008, vol. 42, no. 7, pp. 1371-1388.

[16] W. Turner et al., "A combined energy and IAQ assessment of the potential value of commissioning residential mechanical ventilation systems," Build Environ., 2013, vol. 60, pp. 194-201.

[17] H. Özkaynak, "A population exposure model for particulate matter: case study results for PM2.5 in Philadelphia, PA," J Expo Sci Environ Epidemiol., 2001, vol. 11, no. 6, pp. 470-489.

[18] P. Fabian, G. Adamkiewicz, and J. Levy, "Simulating indoor concentrations of $\mathrm{NO}_{2}$ and PM2.5 in multifamily housing for use in health-based intervention modelling," Indoor Air, 2011, vol. 22, no. 1, pp. 12-23.

[19] N. Klepeis et al., "Determining size-specific emission factors for environmental tobacco smoke particles," Aerosol Science and Technology, 2003, vol. 37, no. 10, pp. 780-790.

Copyright $\odot 2019$ by the authors. This is an open access article distributed under the Creative Commons Attribution License which permits unrestricted use, distribution, and reproduction in any medium, provided the original work is properly cited (CC BY 4.0).

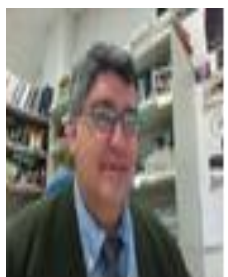

Roberto San José is professor of the Technical University of Madrid. He is director of Environmental Software and Modelling Group in the Computer Science School of UPM. He has more than 300 scientific publications in relevant Journal Citation Index Journal. He completed his PhD in 1982 related to the unstable surface turbulent boundary layer parameterisation. He has been involved in air pollution modelling mainly using three-dimensional mesoscale models, such as MM5 and CMAQ.. He has been a Full Professor since 2001.

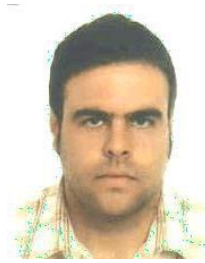

Juan Luis Pérez graduated in computer sciences at Computer Science School of the Technical University of Madrid in 2000, and in 2005, he defended a PhD thesis related to operational modelling of the MM5-CMAQ system over the internet. He has been an Associate Professor since 2005 and Permanent Professor since 2011. He is involved in some international and national research projects about atmospheric simulations and has published many papers in journals and conference proceedings.

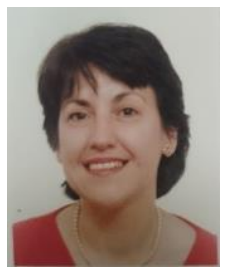

Libia Pérez is telecommunication engineering. She made the $\mathrm{Ph}$. D. in 1982 on relation to a new method for character recognition using geometric and topological structures. She has been involved in different EU projects during the last de cade joing the Environmental Software and Modelling Group in the Computer Science School of the Technical University of Madrid.

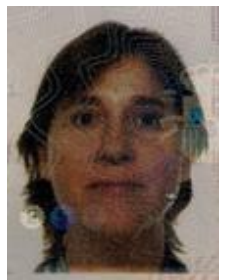

Rosa María Gonzalez Barras is Ph.D in physics. Rosa M. González is an associate professor of physics and numerical analysis in the Department of Geophysics and Meteorology of the Faculty of Physics of the Complutense University (UCM). She has participated several EU projects on relation to ai quality and climate modelling. She is an expert on MATLAB and FORTRAN programming. 